\title{
LAS TIC EN LA EDUCACIÓN: ANÁLISIS EN UNA UNIVERSIDAD ARGENTINA
}

\author{
SEBAstián NOVOMISKY' \\ Universidad Nacional de La Plata, Argentina / sebastiann@perio.unlp.edu.ar \\ GLADYS MANCCINI ${ }^{2}$ \\ Universidad Nacional de La Plata, Argentina / gladysmanccini@gmail.com \\ GISELA ASSINNATO ${ }^{3}$ \\ Universidad Nacional de La Plata, Argentina / gisela183@gmail.com \\ AdRIANA COSCARELLI ${ }^{4}$ \\ Universidad Nacional de La Plata, Argentina / adrianacoscarelli@lvm.unlp.edu.ar
}

\author{
Recibido:30/3/2019 / Aceptado:30/7/2019 \\ doi: 10.26439/contratexto2019.n032.4619
}

Resumen. Ante los cambios generados por las tecnologías digitales en los modos de construir el conocimiento, resulta fundamental el rol de las instituciones educativas en la reconfiguración de sus prácticas docentes. Este artículo pretende visibilizar posiciones de profesores universitarios ante la innovación digital y confrontarlas con propuestas de actualización profesional. El diseño metodológico posibilita un estudio exploratorio sobre 45 profesores de la Universidad Nacional de La Plata (UNLP), Argentina, mediante un cuestionario online acerca de usos, prácticas y percepciones asignadas a las tecnologías en la enseñanza. Además, se seleccionan, como unidad de observación, tres propuestas de capacitación implementadas por dicha academia y se efectúa su descripción sistemática. De la articulación entre las demandas y posiciones docentes, y de los rendimientos y devoluciones de las propuestas se obtienen conclusiones provisorias: aunque los profesores mantienen un vínculo recurrente con

\footnotetext{
1 Doctor en Comunicación por la Universidad Nacional de La Plata, Argentina. http://orcid.org/0000-00025705-9332

2 Licenciada en Comunicación Social por la Universidad Nacional de La Plata, Argentina.

3 Magíster en Tecnología Informática Aplicada a la Educación por la Universidad Nacional de La Plata, Argentina. http://orcid.org/0000-0003-2457-6832

4 Magíster en Tecnología Informática Aplicada a la Educación por la Universidad Nacional de La Plata, Argentina. http://orcid.org/0000-0003-2457-6832
} 
herramientas digitales, estas prácticas disminuyen ante mediaciones que promueven capacidades más creativas. Si bien en la formación interna se evidencian procesos con incorporación crítica de recursos digitales, existen contradicciones entre las posiciones manifestadas por los profesores y la adhesión a las capacitaciones. Esto permite discutir desafíos que la educación superior afronta al querer generar procesos sostenidos y genuinos de innovación.

Palabras clave: tecnologías digitales / capacitación docente / educación superior y universitaria / estrategias didácticas

\section{ICTS IN EDUCATION: AN ANALYSIS IN AN ARGENTINE UNIVERSITY}

Abstract. Given the changes generated by digital technologies in the ways of building knowledge, the role of educational institutions is fundamental in the reconfiguration of their teaching practices. This article aims to reveal the positions of university professors in the face of digital innovation and compare them with proposals for professional updating. The methodological design enables to conduct an exploratory study on 45 professors from the National University of La Plata (UNLP), Argentina, using an online questionnaire about the uses, practices and perceptions assigned to teaching technologies. In addition, three training proposals implemented by said academy are selected, as an observation unit, and a systematic description of such initiatives is carried out. From the articulation between the demands and teaching positions, and the performance and proposal returns, provisional conclusions are obtained: even though professors maintain a recurrent link with digital tools, these practices diminish in front of mediations that promote more creative capacities. Although processes that critically include digital resources are evident in internal training, there are contradictions within the positions expressed by professors and the adherence to trainings. This allows to discuss the challenges that higher education faces when wanting to generate sustained and genuine innovation processes.

Keywords: Digital technologies / teacher training / higher and university education / teaching strategies 


\section{AS TIC NA EDUCAÇ̃̃̃O: ANÁLISE EM UMA UNIVERSIDADE ARGENTINA}

Resumo. Dadas as mudanças geradas pelas tecnologias digitais nas formas de construção do conhecimento, o papel das instituições educativas na reconfiguração de suas práticas de ensino é fundamental. Este artigo tem como objetivo tornar visíveis as posições de professores universitários sobre a inovação digital e compará-los com propostas de atualização profissional. O desenho metodológico permitiu um estudo exploratório em 45 professores da Universidade Nacional de La Plata (UNLP), Argentina, através de um questionário online sobre usos, práticas e percepções atribuídas às tecnologias de ensino. Além disso, três propostas de treinamento foram selecionadas por essa instituição e executadas como uma unidade de observação e descrição sistemática. A partir da articulação entre as demandas e os cargos de ensino, e os rendimentos e retornos das propostas foram obtidas conclusões provisórias: embora os professores mantenham um vínculo frequente com as ferramentas digitais, essas práticas diminuem diante de mediações que promovem capacidades mais criativas. Apesar de que na formação interna se verifiquem processos de incorporação crítica de recursos digitais, também existem contradições entre as posições expressas pelos docentes e a aderência aos treinamentos. Isso permite discutir os desafios que o ensino superior enfrenta quando deseja gerar processos de inovação sustentados e genuínos.

Palavras-chave: Tecnologias digitais / formação de professores / ensino superior e universitária / estratégias metodológicas de ensino 


\section{INTRODUCCIÓN}

Sin duda, ya nadie puede ignorar los desafíos y oportunidades que han generado las nuevas tecnologías sobre los modos de enseñar y aprender en las últimas décadas al transformar significativamente la manera de configurar, construir y difundir el conocimiento. No obstante, muchas instituciones educativas, en sus diferentes niveles, parecen persistir en la conservación de escenarios didáctico-pedagógicos tradicionales, propios de una escuela o de una universidad donde el saber era impartido unidireccionalmente y se concentraba en la figura del docente, los textos de lectura lineal y las pizarras fijas.

Actualmente. como afirma Bilinkis (2014, p. 220), la educación responde aún a métodos, motivaciones y necesidades de siglos pasados: "La escuela no cambia, pero los alumnos sí. Esto da por resultado un cóctel explosivo".

Atentos al desafío nada sencillo de superar esta paradoja de querer educar para el futuro mirando hacia el pasado, es que muchos docentes e investigadores han comenzado a construir nuevos escenarios, diseñando propuestas que permitan recuperar prácticas valiosas de la escuela tradicional integradas a las nuevas, mediadas por tecnologías de la información y de la comunicación (TIC).

Es necesario reconocer el potencial educativo que encierran estas herramientas debido a que pueden tener funcionalidades informativas, instructivas, motivadoras, evaluadoras, investigadoras, expresivas, metalingüísticas y lúdicas (García Valcárcel y González Rodero, 2006, p. 7). Asimismo, resulta crucial asumir que las TIC han provocado un gran desfase en la industria comunicativa, de allí la urgencia, particularmente para quienes nos desempeñamos como profesores en carreras relacionadas con este campo, de actualizar contenidos, soportes, metodologías y prácticas educativas.

Pero también es preciso dar cuenta de las dificultades e incertidumbres que implica la integración de tecnologías digitales en las prácticas educativas. Aun con docentes e instituciones que valoren positivamente y apuesten por la innovación de la enseñanza, la puesta en marcha de estrategias mediadas trae aparejados desafíos en términos de diseños curriculares, disciplinares, didácticos y de gestión y seguimiento de las clases presenciales y virtuales, por mencionar solamente algunos.

Ciertas tensiones que genera el uso de las TIC tienen que ver con los retos pedagógicos que conlleva, pues, su incorporación -ya sea intencional en función de los fines educativos o espontánea- "puede fragmentar el espacio educativo y crear discontinuidades en el tiempo y los ritmos educativos" (Barberá Gregori y Badia, 2005, p. 3).

Frente a estas perspectivas, los objetivos del presente artículo son los siguientes:

a. Realizar un análisis de los resultados obtenidos en encuestas tendentes a explorar los usos, las prácticas y las percepciones que los docentes 
universitarios de comunicación dan a las TIC en la enseñanza, y discutir las oportunidades y barreras que genera esta integración en la preparación inicial de comunicadores.

b. Sistematizar tres propuestas de capacitación implementadas por un equipo de docentes e investigadores de la Facultad de Periodismo y Comunicación Social de la Universidad Nacional de La Plata (FPyCS-UNLP, Argentina), originadas en respuesta a algunas de las demandas detectadas.

c. Elaborar reflexiones y conclusiones de carácter provisorio que se derivan de la articulación entre las demandas, las propuestas institucionales y los resultados obtenidos.

\section{ESTADO DE LA CUESTIÓN}

En este marco de transformaciones y redefiniciones de prácticas, tiempos y roles, y ante la proliferación de los recursos y plataformas online, teóricos del campo consideran necesario que los docentes afinen criterios para determinar qué propuestas, estrategias y herramientas serán las más adecuadas para lograr los objetivos pedagógicos. Esto sucede aun a sabiendas de que los programas informáticos y otras innovaciones tecnológicas de comunicación e información tienen diferentes alcances y limitaciones en cuanto a los formatos que permiten, sus posibilidades para representar y transmitir datos, construir redes, elaboración de contenidos, espacios para relacionarse con otros, etcétera. En este sentido, se sostiene que las propuestas que integran aspectos tecnológicos y pedagógicos requieren que los profesores desarrollen habilidades "que superen la propia tecnología y la reconfiguren de manera creativa para sus propósitos" (Valverde Berrocoso, Garrido Arroyo y Fernández Sánchez 2010, p. 220). De este modo, "abren nuevos horizontes y posibilidades a los procesos de enseñanza y aprendizaje y son susceptibles de generar, cuando se explotan adecuadamente -es decir, cuando se utilizan en determinados contextos de uso-, dinámicas de innovación y mejora imposibles o muy difíciles de conseguir en su ausencia" (Coll, 2009, p. 117).

Tal como plantea Litwin (2005, pp. 13-14), las TIC deberían promover la equidad, la inclusión social, el desarrollo personal y académico de los alumnos, brindando a la comunidad educativa acceso a una información actualizada y promoviendo la comunicación. Asimismo, de acuerdo con esta autora, el soporte brindado por la tecnología es pasible de reconocerse como enmarcando una propuesta, limitándola o expandiéndola según el tipo de tratamiento que posibilita y la manera de utilización por parte del docente para el desarrollo de las comprensiones. Desde esa perspectiva, las tecnologías son herramientas y algo más. 
En consecuencia, creemos que es en el interior de las instituciones donde debe promoverse la toma de conciencia acerca de ese plus que estas herramientas brindan a los profesores, explorando sus potenciales usos no solo para desarrollar la comprensión sino también para motivar y enriquecer la producción del conocimiento, ya sea en la educación presencial y sistemática como en la asistemática y a distancia (e-learning) o mixta (blended-learning).

Tales modalidades no ponen foco en el uso de un dispositivo determinado, sino que reconocen su potencial educativo en la convergencia de soportes digitales. En cambio, otra corriente, el m-learning, denominada también aprendizaje nómada o móvil, se utiliza según Valencia-Arias, Benjumea Arias, Morales Zapata, Silva Cortés y Betancur Zuluaga (2018, p. 762), para definir "las prácticas que aprovechan los dispositivos móviles y las tecnologías inalámbricas de transferencia de datos, a fin de favorecer y extender el alcance de los procesos de enseñanza y aprendizaje (Kuklinski y Balestrini, 2010), influyendo y mejorando los beneficios del e-learning, la relación con el acceso a la información personalizada y al proceso de aprendizaje" (Ozdamli y Cavus, 2011; Valencia, González y Castañeda, 2016).

La literatura existente en la materia permite entender que si bien es cierto que a medida que transcurre el siglo xxI los agentes educativos, y especialmente quienes deben gestionar las actividades académicas y la capacitación docente, comienzan a ocuparse de promover la inclusión de ambas modalidades en la labor cotidiana con los alumnos (con diferentes niveles de compromiso, recursos humanos y tecnológicos, presupuesto e infraestructura disponibles), aún no se ha avanzado demasiado acerca del uso de los dispositivos móviles con fines académicos (mobile learning).

Entre los trabajos existentes relacionados con m-learning, cabe mencionar el de Valencia-Arias et al. (2018), cuyo objetivo fue examinar las actitudes de los docentes universitarios frente al uso de dispositivos móviles con fines académicos en una institución de educación superior de vocación tecnológica de Colombia. Los autores estudiaron los datos obtenidos luego de administrar quince entrevistas semiestructuradas, a partir de tres categorías analíticas: conocimiento, actitudes y habilidades, retos y oportunidades en la implementación de estrategias de mobile learning. Los principales aportes que los entrevistados identificaron al respecto se refieren a la facilitación de la movilidad, la accesibilidad y la interactividad en los procesos educativos. Por otra parte, entre los retos consignaron la falta de promoción por parte de la academia de capacitación docente, la poca autonomía de aprendizaje en los alumnos y las dificultades de accesibilidad de dispositivos móviles adecuados para los estudiantes.

En suma, lo expresado anteriormente respecto de las diversas modalidades en la enseñanza, los desafíos actuales de las instituciones educativas y las potencialidades de las TIC en las prácticas docentes permite diferenciar varias líneas de investigación en 
las que se articulan diversos ejes: a) el análisis de las demandas y concepciones de los alumnos y los profesores, verdaderos protagonistas del cambio de paradigma, en torno a la incorporación de las TIC en el proceso de enseñanza-aprendizaje, b) el diagnóstico de las problemáticas referidas a la política educativo-institucional y a la gestión de dicho cambio, y c) la incidencia y utilidad de las TIC según la modalidad de enseñanza predominante.

De acuerdo con Cabero-Almenara (2014, p. 129), si bien en el campo del aprendizaje virtual son frecuentes los estudios centrados en los estudiantes, resulta esencial desarrollar otros que se enfoquen en los docentes, puesto que estos constituyen el canal por el cual se asegura la apropiación del conocimiento. Es sumamente relevante la observación del autor citado en cuanto al hecho de que "la resistencia en muchas ocasiones a los cambios de paradigma están más vinculados con los formadores que con los aprendices".

A su vez, Noguera, y Vásquez Melo (2012) afirman respecto del uso y el dominio de las TIC que hacen los docentes en apoyo a sus actividades académicas, que estos son muy deficientes, independientemente de la edad, los años dedicados a la docencia, el nivel de escolaridad y el área de conocimiento. Esto deriva en la necesidad de implementar y revisar las políticas de formación cuyos destinatarios sean profesionales de la docencia, a fin de promover el manejo técnico-didáctico de las TIC en cualquier nivel educativo de nuestro país.

En el caso particular de algunas casas de estudios como la Facultad de Periodismo y Comunicación Social de la Universidad Nacional de La Plata (FPyCS-UNLP), dentro de la cual se inscribe nuestra tarea como docentes e investigadores, existe una intencionalidad por parte del equipo de gestión de estimular experiencias y estudios referidos a la incorporación de las TIC en el ámbito universitario. Dan cuenta de ello los trabajos de investigación de Guiller y Arce, ya sea referidos a la formación docente universitaria en entornos educativos virtuales $(2013,2015)$ o al modo en que se ha ido construyendo un espacio propicio a la formación docente universitaria permanente para la virtualidad desde una perspectiva crítica, comunicacional y pedagógica, acompañando a los docentes en el pasaje de "profesores/as presenciales" a "docentes tutores virtuales" (Guiller y Arce, 2017).

En este marco, se definió un modelo de hibridación educativa que direcciona la adaptación de los entornos virtuales de enseñanza y aprendizaje (EVEA), sitios y herramientas disponibles en la facultad, a las finalidades y requerimientos de los profesores y estudiantes, de modo de reconfigurarlos en espacios de diálogo, intercambio y construcción colectiva. Se cree fundamental, en este sentido, que la tecnología se ponga al servicio de la formación y que los docentes sean autores de sus propuestas y tomen las decisiones pedagógicas y didácticas necesarias (Guiller y Arce, 2015).

De este modo, la institución se encuentra inmersa en un proceso que conlleva retos diversos en la gestión institucional y en las cátedras, dando cuenta de que la temática 
se enmarca dentro de los temas en agenda del establecimiento, pues las propuestas formativas buscan dar respuestas a reconfiguraciones en el horizonte laboral de los comunicadores educadores y a transformaciones y desafíos que le impone la cultura digital a la educación superior y a la formación de formadores.

La presentación de estas iniciativas no implica que se trate de desafíos saldados en la institución, sino de cambios en proceso. Por lo cual, es preciso inferir que se podrían encontrar tanto fortalezas como tensiones en su interior; así como la coexistencia de condiciones heterogéneas - y hasta con ciertas contradicciones- en las que la comunidad educativa está desarrollando modalidades híbridas de enseñanza y aprendizaje.

Ante tales inquietudes es preciso que se realicen estudios que permitan sistematizar cómo el cuerpo docente está posicionándose frente a esta perspectiva de innovación educativa y, al mismo tiempo, qué tipo de propuestas formativas se están llevando a cabo y cómo son recibidas por los docentes. El cruce de esta información resultante podría devenir en conocimiento valioso para la institución, así como para otras casas de estudio que estén atravesando procesos similares.

\section{METODOLOGÍA}

A la luz de las concepciones recogidas en el estado de la cuestión, se realiza un diseño metodológico que nos permite un estudio exploratorio sobre características y funciones que un grupo de docentes de la FPyCS-UNLP, Argentina, atribuyen a las TIC en la enseñanza. Asimismo, el diseño contempla abordar ejes de sistematización de propuestas de capacitación implementadas en la institución y sus resultados.

La inquietud acerca de cómo los profesores de la FPyCS-UNLP incluyen en sus procesos de enseñanza las tecnologías digitales deriva en la definición - de acuerdo con la literatura revisada anteriormente- de tres ejes de análisis: el uso de TIC como propuesta de las cátedras, las estrategias didácticas que integran las TIC y las percepciones de los docentes hacia las TIC.

El estudio fue llevado a cabo en el marco de un diagnóstico institucional desde la Dirección de Profesorado en Comunicación Social (FPyCS-UNLP) y de la tesis de maestría de Assinnato (2018). Asimismo, este relevamiento fue contrastado con un estudio paralelo con profesores de la Universidad de Lima (Perú), cuyos resultados se sintetizan en Assinnato, Mateus y Novomisky (2018).

Para obtener el corpus de datos necesario se creó un cuestionario que incluía 17 preguntas cerradas y tres abiertas, agrupadas en cuatro secciones.

En primer lugar, se configuraron tres interrogantes para obtener datos generales de los profesores (edad, cargo y asignatura en la que se desempeñan). Estos se consideran 
como variables de entrada, ya que permiten determinar algunas características de la muestra.

La sección dos, "Uso de TIC como propuesta de las cátedras", está constituida por cinco ítems. La sección tres, "Estrategias didácticas", está formada por cuatro preguntas, y la sección cuatro, "Posiciones frente a la integración de TIC en educación", está compuesta por ocho interrogantes.

La construcción de este instrumento se basó en modelos que presentan los estudios de Nóbile y Sanz (2014), Cabello (2006) y Ros (2014). No obstante, se debieron redefinir preguntas e, incluso, crear nuevas para responder a los criterios de este artículo.

En esta línea, se adoptaron diversas escalas para estructurar los interrogantes: de frecuencia de usos de TIC (nunca, ocasionalmente, a veces, casi siempre y siempre), de valoración de prácticas educativas con/en TIC (nada, muy poco, algo, bastante, muchísimo), de autopercepción de saberes y habilidades digitales (alto, medio y bajo), de niveles de acuerdo respecto a posiciones frente a TIC (totalmente en desacuerdo, desacuerdo, indiferente, de acuerdo, totalmente de acuerdo) y de opciones respecto a disposiciones personales en torno a la integración de modalidades híbridas de formación (sí, no, tal vez).

Se formó una muestra de 45 profesores, que respondieron el cuestionario desarrollado en un formulario de la herramienta Google Forms. El total de participantes de esta instancia del estudio de caso representa el $56 \%$ del cuerpo docente del ciclo superior de una de las carreras que ofrece esta casa de estudios, el Profesorado en Comunicación Social.

Se definió un tipo de muestreo aleatorio, mediante el cual se buscó que los distintos componentes del universo observable tuvieran iguales posibilidades de ser seleccionados. Para garantizar esta llegada, se contactó por un lado a la totalidad de profesionales que se desempeñan con cargos rentados como educadores en distintos equipos pedagógicos del Profesorado en Comunicación Social (80 docentes). Este acercamiento se realizó vía correo electrónico durante los meses de octubre y diciembre del 2017. La convocatoria a participar era voluntaria y anónima. Se logró que más de la mitad de los contactados respondieran la encuesta online.

En cuanto a la sistematización de las capacitaciones que se llevan a cabo desde la institución, se define la realización de una descripción sistemática a partir de dar cuenta de características de dichas iniciativas, en materia de objetivos, contenidos, metodología y destinatarios.

Se definió una muestra constituida por tres experiencias, desarrolladas entre el 2017 y el 2018, en coincidencia con los plazos definidos para la implementación de la encuesta descrita anteriormente. Se trata, además, de las últimas capacitaciones (a la fecha de este artículo) desarrolladas conjuntamente desde tres dependencias de la facultad: 
la Dirección del Profesorado en Comunicación Social y la Dirección de Capacitación Docente, dependientes de la Secretaría Académica, y el área de Educación a Distancia.

Los resultados fueron analizados a partir de las siguientes variables: cantidad, disciplina, rol y nivel de enseñanza en que se desempeñan los inscritos, alcances de la oferta de capacitación, disponibilidad de tecnología e infraestructura, acompañamiento institucional, aplicabilidad o posibilidad de transferencia de las producciones finales del curso realizado y valoración por parte de los asistentes.

Para la constitución de este corpus de datos, se requirió de la revisión de los proyectos de cada iniciativa, el análisis documental de trabajos realizados por los cursantes y la observación de los resultados de encuestas que los docentes a cargo de cada iniciativa implementaron tanto al comenzar como al finalizar el trayecto formativo.

Vale mencionar que los usos, prácticas y percepciones que los docentes atribuyen a las TIC se analizan por separado de las experiencias de formación realizadas en la institución (según sus instrumentos de origen) para luego establecerse cruces de resultados que nos permitan la elaboración de reflexiones finales.

\section{PUNTO DE PARTIDA: LOS DOCENTES FRENTE A LAS TIC}

Este muestreo exploratorio se llevó a cabo mediante encuestas a 45 docentes del Profesorado en Comunicación Social (más del 50 \% del cuerpo docente del tramo orientado de la carrera). Las edades de los participantes oscilaron entre 23 y 67 años, con un promedio de 40,3 años.

A continuación, se consigna una síntesis de los ejes más relevantes analizados a los fines de este artículo y los resultados elaborados a partir de ellos:

En referencia a los usos que los docentes atribuyen a las TIC, se relevaron frecuencias de manejo de espacios digitales para la comunicación dentro de las cursadas, para la realización de actividades con sus alumnos y respecto de la utilización de materiales educativos.

Sobre la comunicación mediada de modo digital en las cátedras de los docentes encuestados, se observa que el correo electrónico es la herramienta más recurrente. En segundo lugar, los entornos virtuales de enseñanza y aprendizaje (EVEA) o espacios institucionales. En tercer lugar, las redes sociales; en cuarto lugar la mensajería instantánea y, por último, las reuniones sincrónicas vía Skype, Hangout. 


\begin{tabular}{|c|c|c|c|c|c|}
\hline \multirow{3}{*}{\multicolumn{2}{|c|}{$\begin{array}{l}\text { REUNIONES SINCRÓNICAS } \\
\text { MENSAJERÍA O FORO DE UN EVEA }\end{array}$}} & \multirow{2}{*}{\multicolumn{3}{|c|}{$82 \%$}} & \multirow{2}{*}{$11 \% \quad 7 \%$} \\
\hline & & & & & \\
\hline & & & $53 \%$ & $20 \%$ & $4 \% 11 \%$ \\
\hline CHAT O MENSAJE & ERÍA INSTANTÁNEA & $38 \%$ & $22 \%$ & $20 \%$ & $16 \%$ \\
\hline MURO O MENSAJE & RÍA DE RED SOCIA & $36 \%$ & $11 \%$ & $22 \%$ & $16 \%$ \\
\hline COR & RREO ELECTRÓNIC & $9 \% 7 \% \quad 13 \%$ & & $71 \%$ & \\
\hline & Correo electrónico & $\begin{array}{c}\text { Muro o mensajería } \\
\text { de red social }\end{array}$ & $\begin{array}{l}\text { Chat o mensajería } \\
\text { instantánea }\end{array}$ & $\begin{array}{c}\text { Mensajería o foro } \\
\text { de un EVEA }\end{array}$ & $\begin{array}{l}\text { Reuniones } \\
\text { sincrónicas }\end{array}$ \\
\hline Nunca & 0 & 16 & 17 & 24 & 37 \\
\hline - Ocasionalmente & 4 & 5 & 10 & 5 & 5 \\
\hline A veces & 3 & 7 & 9 & 9 & 3 \\
\hline Casi siempre & 6 & 10 & 2 & 2 & 0 \\
\hline Siempre & 32 & 7 & 7 & 5 & 0 \\
\hline
\end{tabular}

Figura 1. Porcentajes y cantidades de uso de herramientas de comunicación Fuente: Assinnato, 2018

En cuanto a la utilización de materiales educativos como propuesta de las cátedras, se destaca que es extensiva a casi la totalidad de la muestra el uso continuo de textos digitales y videos. Las imágenes y las presentaciones digitales son los recursos utilizados en tercer y cuarto lugar. Los audios, en cambio, aparecen en quinto lugar. En menor medida, se referencian recursos interactivos y simuladores.

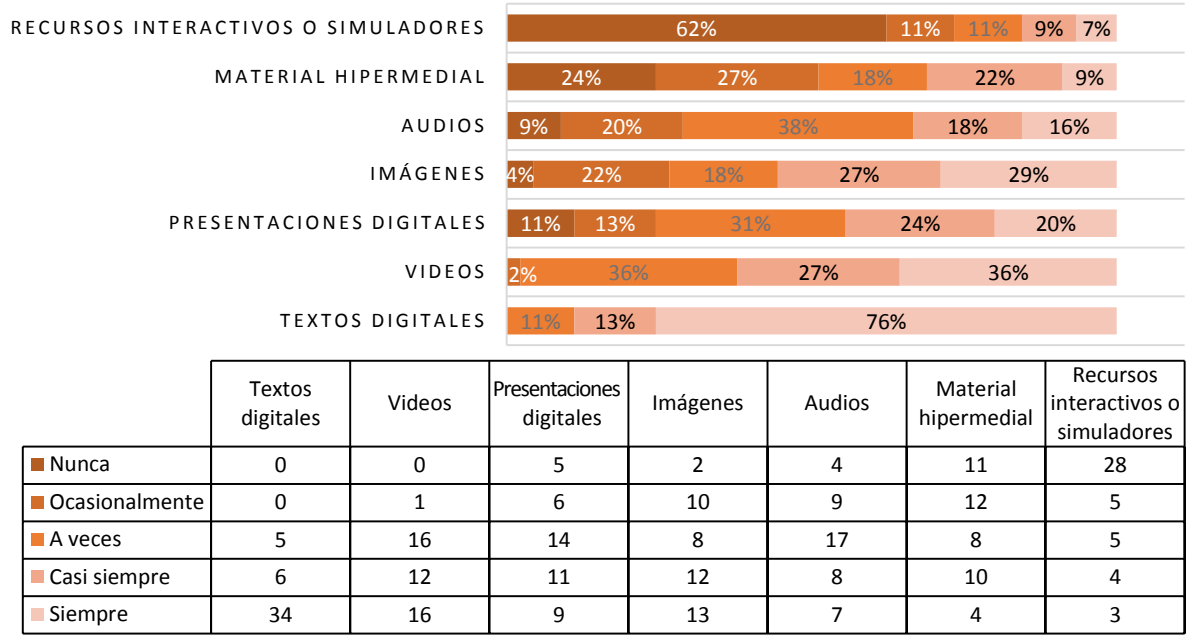

Figura 2. Porcentajes y cantidades de uso de materiales educativos

Fuente: Assinnato, 2018 
Respecto del uso de plataformas de trabajo para la realización de actividades didácticas, se observan decisiones disímiles entre los educadores: los docentes seleccionan en primer lugar los espacios de almacenamiento compartido (Google Drive u otros). Las redes sociales son las plataformas que aparecen en tercer nivel de usos y los entornos virtuales de enseñanza y aprendizaje (EVEA) en cuarto lugar. Por último, se seleccionan las wikis o blogs.

En lo que se refiere a las estrategias didácticas empleadas por los docentes con las TIC, se indaga sobre actividades innovadoras que realizan los educadores, así como sobre los momentos en que las tecnologías digitales están presentes en la práctica docente.

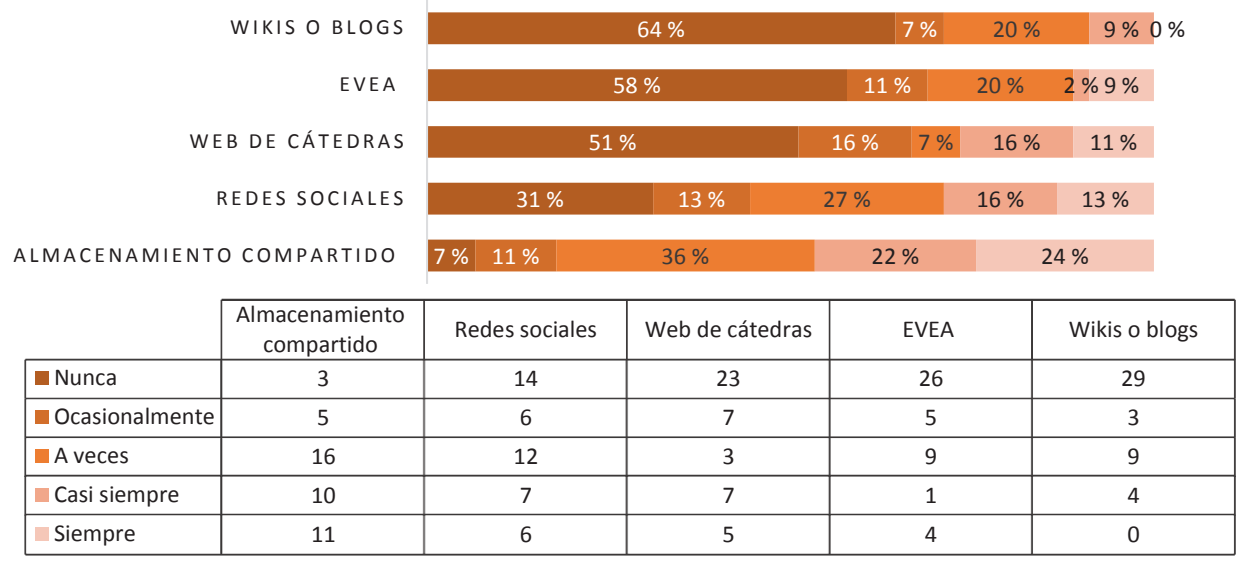

Figura 3. Cantidades y porcentajes de uso de entornos para la realización de actividades didácticas y seguimiento

Fuente: Assinnato, 2018

Con una recurrencia baja, los profesores señalan que adaptan materiales o recursos digitales producidos por terceros y rara vez utilizan juegos como parte de su práctica pedagógica. En cuanto a las acciones de índole colaborativa (compartir material y producir documentos) su aplicación es mayor que la descrita anteriormente.

En tanto, se puede observar que la presencia mayor de las tecnologías digitales está en el momento de la preparación de la clase (búsqueda y selección de información, principalmente), en menor medida durante las clases $y$, en tercer término, como una extensión de estas. 


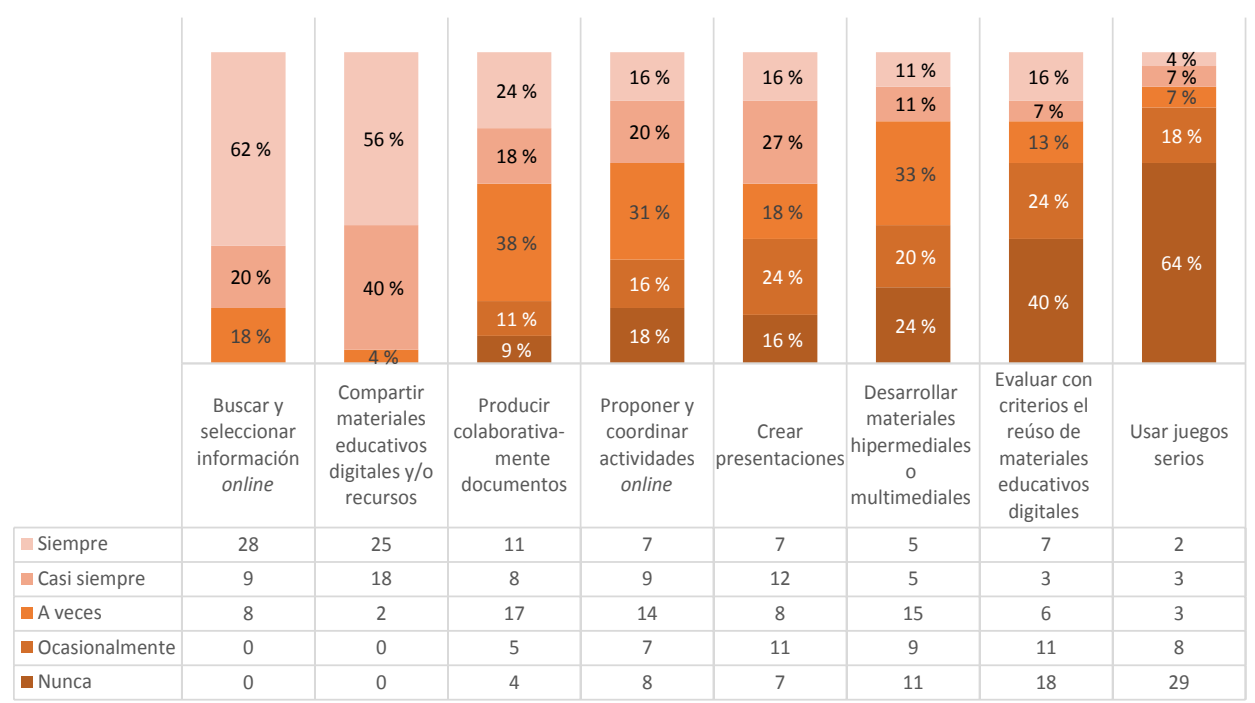

Figura 4. Porcentajes y cantidades de respuestas sobre actividades que realizan los docentes utilizando TIC

Fuente: Assinnato, 2018

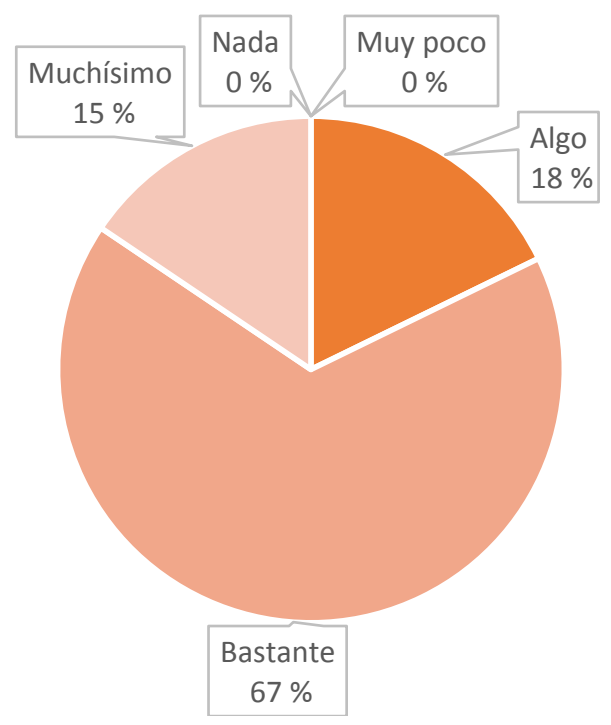

Figura 5. Porcentajes y cantidades de respuestas sobre momentos en que los profesores utilizan las TIC en la práctica docente

Fuente: Assinnato, 2018 
Por último, se indagaron percepciones de los docentes, para lo cual se destacan preguntas sobre si el trabajo mediado ha enriquecido sus clases, logros que los docentes identifican a partir de la mediación digital en sus clases y también dificultades percibidas en tales instancias.

Respecto a las posiciones de los docentes frente a la integración de TIC, el reconocimiento de la posibilidad de enriquecer la enseñanza a partir de la incorporación de actividades digitales ofrece una percepción crítica en el cómputo general. Aún no existiría, por lo tanto, una valoración plena de la necesidad de actualización de los formatos de trabajo áulico, si bien resulta necesario incorporar nuevas estrategias para potenciar la tarea docente y para consolidar la interpelación de los estudiantes.

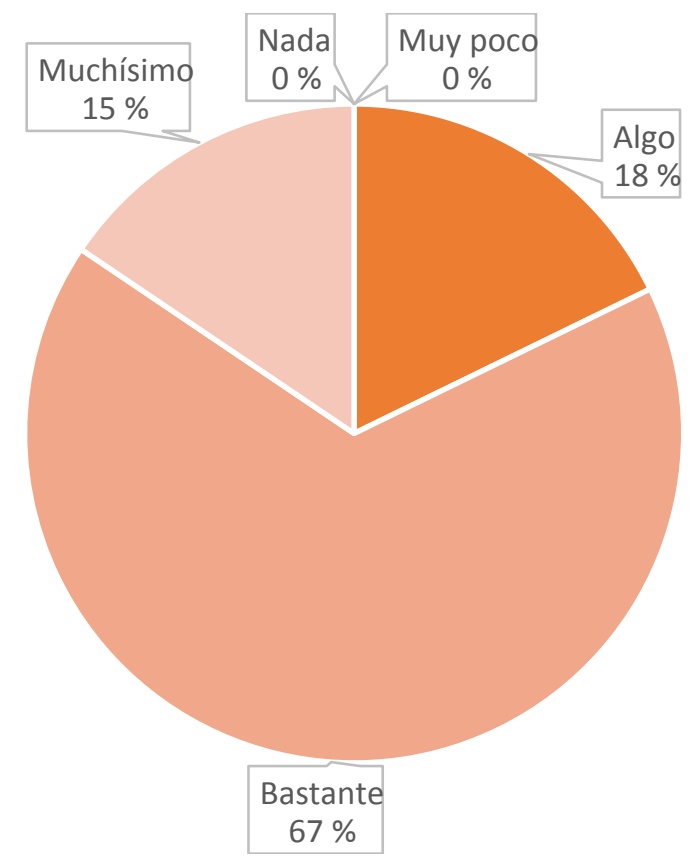

Figura 6. Porcentajes y cantidades de respuestas sobre si el trabajo mediado ha enriquecido sus clases

Fuente: Assinnato, 2018

Con relación a los logros, los docentes de la UNLP valoran más el trabajo mediado con otros colegas que la propia integración de TIC en el aula. Esto podría deberse a la incipiente integración de TIC en la carrera de La Plata y, por lo tanto, el reconocimiento de algunas limitaciones de cómo esto impacta en los estudiantes, en cuanto al soporte tecnológico, por un lado; y al modo de organización y comunicación entre docentes, por 
otro, que reorganizan el trabajo entre pares, pero no la didáctica áulica. Otro aspecto que llama la atención es que el trabajo con referentes institucionales es el menos frecuente. Quizás esto se deba al hecho de que transversalmente el problema de la inclusión digital es percibido como un tema didáctico propio de cada cátedra y docente, pero no abordado institucionalmente.

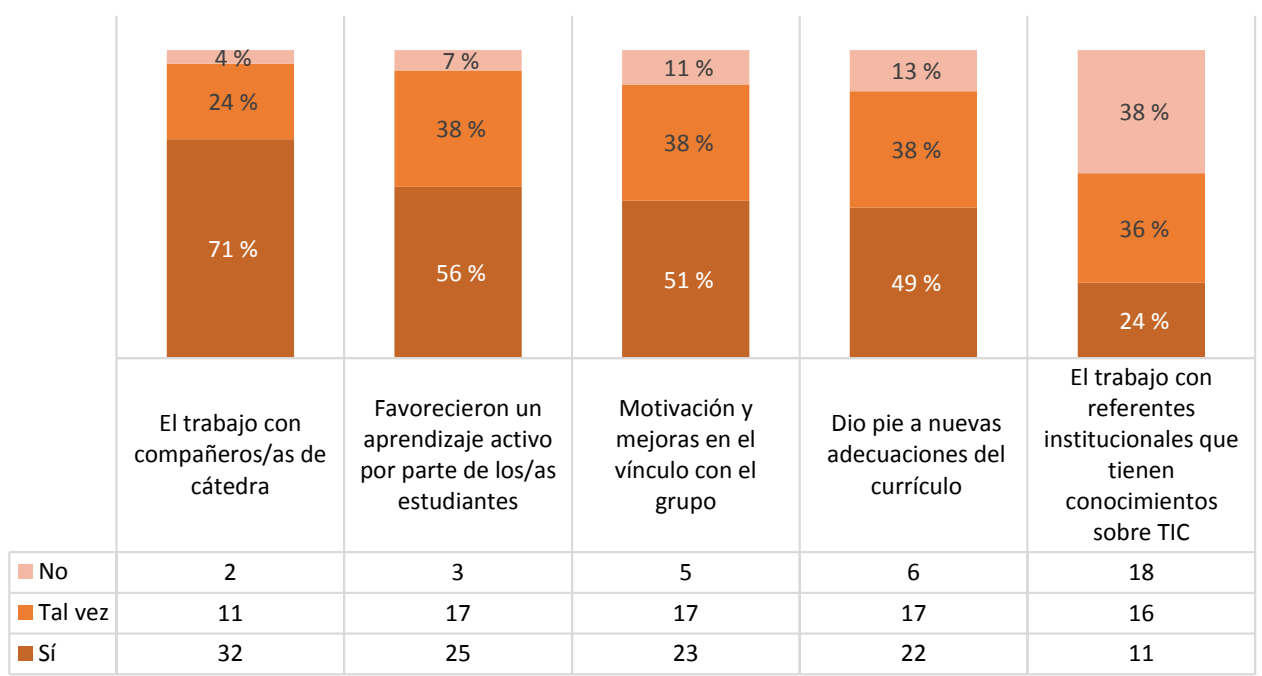

Figura 7. Logros percibidos por los docentes sobre la integración de las TIC en la enseñanza Fuente: Assinnato, 2018

En relación con las dificultades expuestas por los docentes de la UNLP, se destaca la falta de disposición de equipamientos técnicos. Aquí podemos encontrar condiciones de accesibilidad, conectividad y repertorio de recursos tecnológicos, que no dependen únicamente de la tecnología disponible en la institución, sino también provista por los propios estudiantes (teléfonos inteligentes con conectividad, notebooks y netbooks, tablets, etcétera). Es posible que la percepción de las limitaciones en el uso de las tecnologías por falta de soporte, se asocie con una dificultad de reconocer otras opciones que van más allá del aula.

Resulta significativo que en dicha universidad se consigne la apatía y la distracción de los estudiantes, aspecto central del debate, ya que paradójicamente las TIC pueden motivar más a los estudiantes siempre que los profesores sepan interpelarlos y planificar en un marco de convergencia tecnológica, recuperando los saberes de los jóvenes al respecto. No obstante, creemos que estas manifestaciones generales de apatía o distracción podrían considerarse más bien como fenómenos que ponen en evidencia la necesidad de estímulos constantes y variados, propia de las nuevas generaciones. Por 
otra parte, los docentes encuestados consignan como una preocupación el tiempo extra que requiere la integración de TIC en el aula dentro de sus posibilidades laborales.

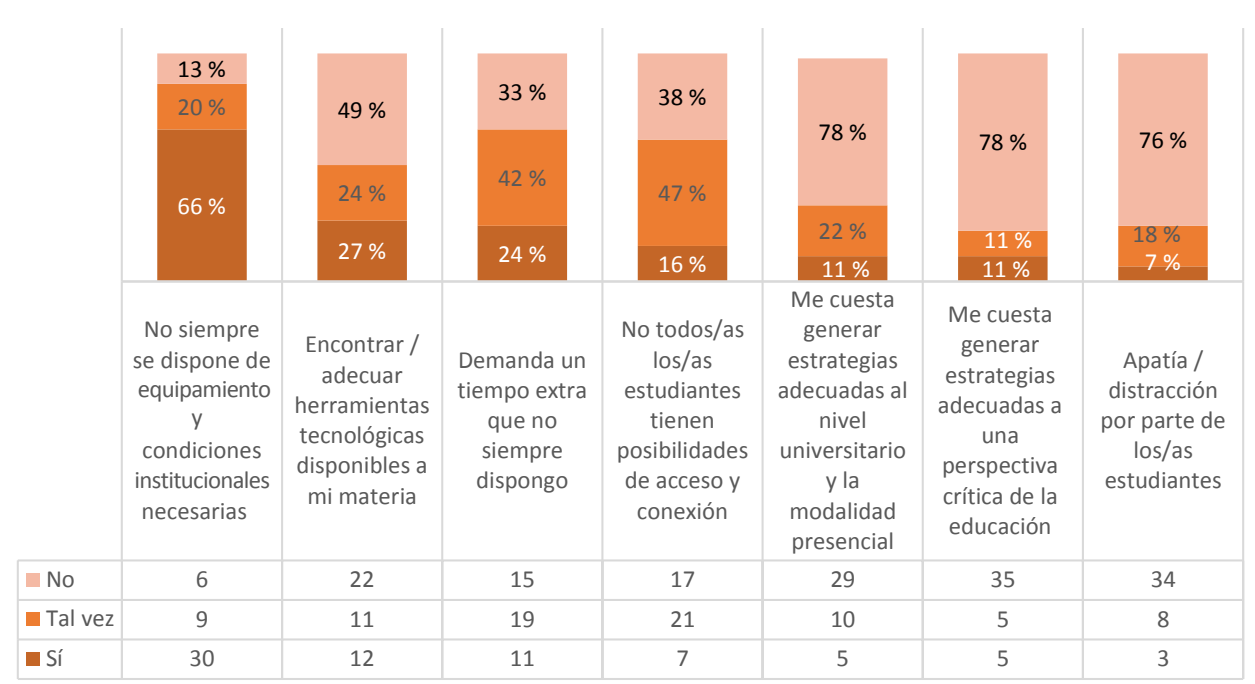

Figura 8. Porcentajes y cantidades de respuestas sobre las dificultades percibidas Fuente: Assinnato, 2018

Tal como se plantea en Assinnato (2018) y en Assinnato, Mateus y Novomisky (2018), los resultados de los cuestionarios permitirían observar que si bien los profesores mantienen un vínculo recurrente con diversas herramientas digitales, estas prácticas disminuyen en el caso de mediaciones que promueven capacidades creativas, experimentales y lúdicas.

Por otra parte, se pueden vislumbrar ciertas tensiones entre las posiciones de los docentes, puesto que si bien valoran positivamente el uso didáctico de las herramientas digitales, no demuestran una convicción plena de la necesidad de actualizar los formatos y las metodologías vigentes. Asimismo, los informantes advierten algunas dificultades que asocian a la integración de TIC, lo cual posibilitaría pensar desafíos a escala institucional que reviertan esta situación.

En consecuencia, podemos sostener que resultan necesarios programas de formación dentro de los espacios institucionales como parte de las tareas asignadas a los docentes en servicio. Dejarlas libradas a la voluntad individual o de los equipos de cátedra provocaría, sin duda, diferencias sustanciales no solo en cuanto a las demandas de tiempo sino también a la calidad en la formación. Consideramos que se trata de una verdadera necesidad institucional: orientar la integración didáctica de las TIC aportando 
propuestas que se adapten a los diversos contextos (contenidos, objetivos y demandas de cada cátedra) y garantizar el acompañamiento de los docentes una vez concretadas las instancias de formación o actualización tecnológica. Esto permitirá capitalizar la disposición favorable detectada por el estudio consignado (Assinnato, 2018; Assinnato, Mateus y Novomisky 2018), lo cual resultará posible en la medida que se logre una mayor concienciación en los profesores acerca del impacto de las TIC sobre la realidad situada, en general, y la educativa, en particular.

\section{PROPUESTAS DE CAPACITACIÓN EN EL ÁMBITO INSTITUCIONAL}

La Dirección de Educación a Distancia en la Facultad de Periodismo y Comunicación Social fue establecida en el 2007, luego de unos años de que fuera creada la dirección homónima en la UNLP. El objetivo principal de la institucionalización de este espacio, tal como afirman Guiller y Arce (2013, p. 19), fue atender a las necesidades en los niveles de grado y posgrado de la Unidad Académica: "contar con un espacio de asesoramiento, capacitación y seguimiento destinado a los docentes, de carácter pedagógico y comunicacional con relación al uso de herramientas informáticas y de comunicación en procesos formativos".

Es por ello que desde la Secretaría Académica comienzan a impulsarse actividades tendentes a concretar nuevas propuestas que surgirán con el transcurso de los años gracias al trabajo articulado de tres áreas: Capacitación Docente, Profesorado en Comunicación Social y Educación a Distancia.

Atendiendo, pues, a la compleja vinculación entre la educación, los medios y las TIC, ante las transformaciones descritas previamente y en un entramado político, tecnológico y cultural particular, es que surgen y se desarrollan en la FPyCS de la UNLP diversas iniciativas de actualización docente que intentaremos resumir en este apartado.

En una primera instancia, se diseñaron cursos de capacitación a distancia y cerrados, es decir, pensados para actualizar al personal de la misma institución. En el 2017, a través de Aulasweb de la UNLP se propone el curso "Más allá del aula: nuevas estrategias de acompañamiento al alumno", a cargo de la profesora Adriana Coscarelli. Respondió a dos necesidades constantes: actualización docente e incorporación de herramientas mediadas por nuevas tecnologías a fin de facilitar el acompañamiento y la permanencia de alumnos de la Facultad de Periodismo y Comunicación Social. Más tarde, en el primer semestre del 2018, se decidió repetir la experiencia con leves variantes, haciéndola extensiva a adscriptos, auxiliares docentes, jefes de trabajos prácticos y adjuntos de todas las materias del ciclo básico.

En una segunda instancia, en el segundo semestre del 2018, se convoca un curso semipresencial y abierto, a fin de que pudieran participar también docentes de otras instituciones y de todos los niveles: educación primaria y educación secundaria, estudiantes 
y graduados del Profesorado en Comunicación Social (FPyCS de la UNLP), y estudiantes y graduados de profesorados universitarios y terciarios en general. Este curso, "Educación y TIC: innovaciones posibles en escenarios reales", a cargo de la magíster Gisela Assinnato, con la colaboración de la Prof. Adriana Coscarelli y la visita de especialistas invitados, se propone articular la reflexión conceptual con la producción individual y colectiva. En el marco de políticas destinadas a generar transformaciones en la escuela pública, bajo la meta de promover aprendizajes y disminuir brechas educativas y digitales, esta nueva propuesta invitó a reflexionar sobre lo real y lo posible respecto de los planes y programas destinados a incorporar notebooks y TIC en las aulas, a pensar continuidades y rupturas en relación con dichas políticas públicas y, particularmente, en los roles y desafíos que docentes y maestros creemos necesario asumir.

En esta oportunidad, se plantea, pues, repensar lo que acontece en las aulas y más allá de estas, en los actores escolares, en la relación entre los estudiantes, y entre estos y los docentes, en los procesos de enseñanza-aprendizaje, cuando entran en juego las mediaciones tecnológicas, comunicativas y pedagógicas.

\section{SISTEMATIZACIÓN DE LAS EXPERIENCIAS}

Las experiencias llevadas a cabo en la FPyCs de la UNLP presentaron ciertas diferencias en cuanto al entorno (virtual/semipresencial), al alcance de la convocatoria (cerrado y destinado a docentes universitarios / abierto para docentes de nivel primario, secundario, terciario y universitario), a la plataforma educativa utilizada en su diseño (Moodle/ Edmodo) y a la cantidad de agentes educativos involucrados en la experiencia (una única profesora / una docente responsable con otra colaboradora y especialistas invitados).

Estas variables, sin duda, incidieron en la metodología implementada:

Para el primer curso, desarrollado en clases virtuales semanales con una carga horaria total de 40 horas reloj aproximadamente - según los ingresos al aula virtual, el ritmo y dedicación de cada alumno-, se conformó un grupo cerrado en Moodle con acceso a la bibliografía y al material didáctico diseñado por la docente. Se combinaron textos, imágenes, audios y videos que funcionaron como soporte teórico y tutoriales o, en otras oportunidades, como punto de partida para motivar actividades diversas: foros de discusión, wikis colaborativas, tareas individuales, murales grupales, encuestas, glosarios, etc. Las tareas concluyeron con un trabajo final a modo de evaluación integrada en el que los participantes recuperaron y profundizaron lo hecho a lo largo de dos meses.

Para el segundo curso, cuya carga fue de 35 horas distribuidas en cinco encuentros presenciales y trabajos a distancia, se implementó una dinámica que, por una parte, integrara en las clases presenciales el desarrollo de aspectos teórico-conceptuales a cargo de la docente responsable del curso y de especialistas invitados (encuentros 
con las doctoras María Victoria Martin ${ }^{5}$ y María Mercedes Martín ${ }^{6}$ y videoconferencia del doctor Julio César Mateus ${ }^{7}$ ), y, por otra, motivara la participación e interacción de los participantes. En cuanto a la parte práctica, se desarrollaron trabajos de resolución en entornos virtuales (plataforma educativa Edmodo), a partir de la incorporación de bibliografía, presentaciones, murales, videos y encuestas. Con respecto a la evaluación final, consistió en un trabajo colaborativo integrador que estimuló la recuperación de aspectos teórico-prácticos a través del uso de aplicaciones didácticas mediadas por TIC y permitió compartir los logros de los cursantes a través de una puesta en común en la última clase.

Al mismo tiempo, el segundo curso fue escenario de la elaboración de un material audiovisual a cargo de la TV Universidad Nacional de La Plata (2018), en cuya edición se combinan fragmentos de una clase presencial, aportes de los cursantes y breves entrevistas a uno de los colaboradores especializados en educación y TIC ${ }^{8}$.

Respecto de las herramientas y aplicaciones didácticas que fueron utilizadas en ambos cursos, se destacan las siguientes:

- Learning Apps: a través de esta aplicación se diseñaron ejercicios interactivos, autoinstruccionales y autoevaluativos de manera individual o intracátedra, recuperando temas y prácticas relacionadas con el contenido de cada materia.

- Pow Toon: herramienta para diseñar videos animados de carácter más bien teórico expositivo/informativo que se incorporó para presentar o revisar algunos temas incluidos en el trabajo final.

- Popplet: se utilizó en el trabajo de evaluación final integrador. Mediante este mural construido colaborativamente, cada cátedra o grupo recuperó lo hecho a lo largo del curso virtual con las herramientas y aplicaciones antes presentadas. Esta aplicación permite resumir en una especie de mapa conceptual multimedial e hipertextual contenidos nodulares de cada materia y profundizarlos desde la teoría (links a bibliografía, conferencias, videos, entrevistas, clases grabadas de los docentes, etcétera) o la práctica (ejercicios diseñados en Learning Apps). Para ello los estudiantes deben transitar un recorrido desde la superficie hacia diversas capas de complejidad.

5 Licenciada en Comunicación, magíster en Comunicación y Gestión de Procesos Comunicacionales y doctora en Comunicación por la FPyCS de la UNLP.

6 Coordinadora del Área de Formación y Asesoramiento, Dirección de Educación a Distancia y Tecnologías de la UNLP.

7 Doctor en Comunicación por la Universidad Pompeu Fabra. Máster en Estudios Avanzados en Comunicación Social, magíster en Comunicación y Educación por la Universidad Autónoma de Barcelona y licenciado en Comunicación por la Universidad de Lima.

8 El video forma parte de una serie de materiales audiovisuales del Proyecto Nexos de la UNLP, que se denominó Capítulo 4: Las TIC y está disponible en: https://bit.ly/2rBdhTX (TV Universidad, 2018). 
- Padlet: herramienta que permite almacenar y compartir contenido multimedia, utilizada como otra alternativa para elaborar un muro digital, como un tablón personal o pizarra colaborativa. Admite insertar imágenes, enlaces, documentos, videos, audios, presentaciones, entre otros, por lo que se asemeja a Popplet.

Al mismo tiempo, en el segundo curso se realizó un mapeo de otras herramientas, como nubes de etiquetas, simuladores interactivos, editores de video, animaciones e imágenes, geolocalizadores, asistentes para la creación de presentaciones estáticas

y dinámicas, plataformas para el trabajo colaborativo, aplicaciones para la enseñanza de programación y creación de videojuegos, software para la producción de líneas de tiempo, entre otras.

\section{ALCANCE Y RECEPCIÓN DE LAS PROPUESTAS}

Como se planteó en el diseño metodológico, los resultados fueron analizados a partir de las distintas variables que se desarrollan a continuación.

Interacción de los actores educativos e intercambio de experiencias

En el curso a distancia se observa un aumento progresivo en la cantidad de inscritos y una ampliación en cuanto a la diversidad de cátedras que participan en los cursos y roles docentes. En su mayoría fueron graduados adscriptos y ayudantes diplomados en el primer curso. Luego se sumaron jefes de trabajos prácticos y algunos profesores adjuntos.

En el curso semipresencial se incorporan todos los niveles educativos (primario, secundario, terciario y universitario) y se pasa de la oferta de formación institucional cerrada a la abierta, para dar cabida a docentes de otras instituciones.

En todos los casos se tendió a garantizar la heterogeneidad entre los cursantes, de modo que al interactuar docentes de diferentes cátedras, materias o niveles educativos, según los cursos (de manera presencial en la clase o virtual en los foros), pudiera generarse un intercambio enriquecedor. Esto significó compartir experiencias que recrearan escenas educativas variadas; reflexionar acerca de problemáticas socioculturales, limitaciones de infraestructura y recursos tecnológicos diversos; contar con mayor o menor acompañamiento institucional, tendiendo siempre a la resolución de los conflictos detectados y a la ejecución de propuestas innovadoras mediadas por TIC en escenarios reales, donde educar hacia el futuro fuera una posibilidad y no una utopía.

Evaluación de los respectivos procesos y producciones finales

Durante el desarrollo del primer curso se consideró la participación en los foros de discusión, el glosario y las wikis. También la respuesta a la encuesta inicial, el diseño de 
cuatro actividades autoinstruccionales y autoevaluativas de manera individual, y la construcción en pequeños grupos de un mural colaborativo (intra o intercátedra). Se evaluó, por lo tanto, el trabajo individual durante el proceso y el trabajo colaborativo a través del producto final (Popplet integrador).

En todos los casos las consignas de trabajo tuvieron como requisito recuperar objetivos y contenidos de las respectivas cátedras. En el caso de aquellas que contaron con una mayor participación de docentes y quizá por estar habituadas al trabajo cotidiano en equipo más cohesionado y sostenido, se percibió una mayor calidad en las producciones finales y, consecuentemente, una mayor posibilidad de transferencia.

Ejemplo del material producido por los participantes del curso:

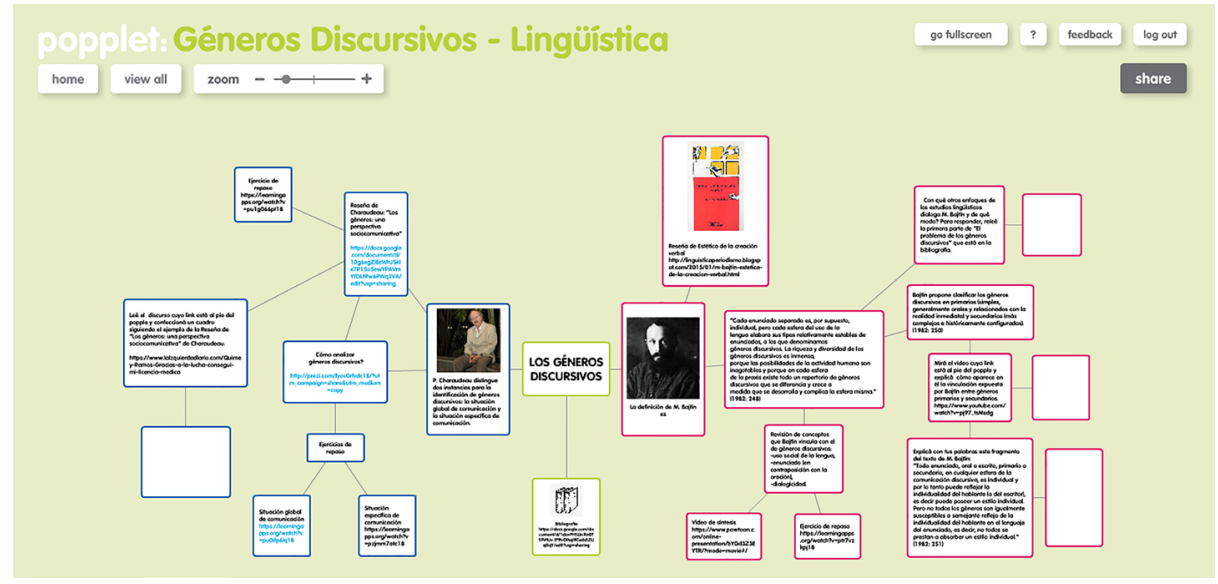

Figura 9. Géneros Discursivos, realizado por la Cátedra Lingüística (FPyCS-UNLP), con recorridos de actividades interactivas y materiales de análisis y apoyo bibliográfico Fuente: Assinnato y Coscarelli (2018) 


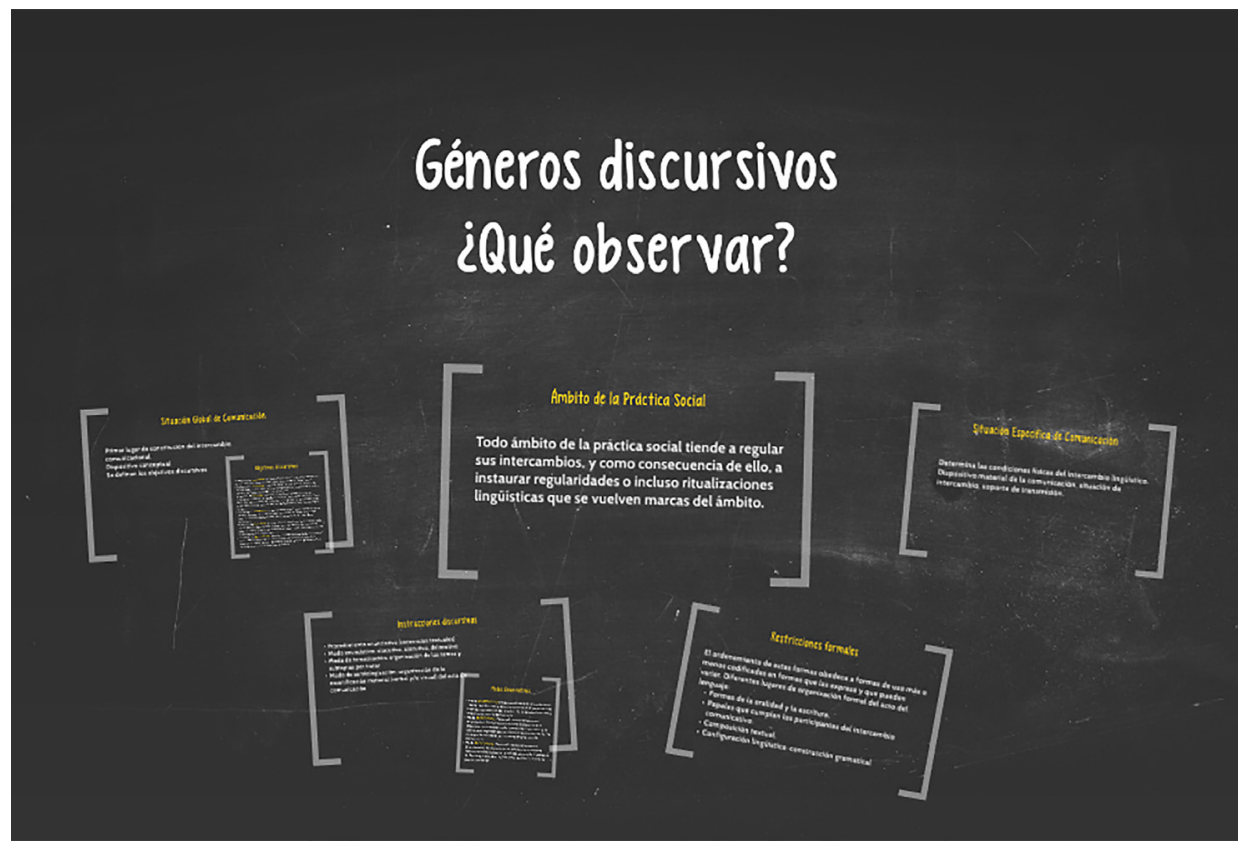

Figura 10. Hipervínculos del material Géneros Discursivos

Fuente: Assinnato y Coscarelli (2018)

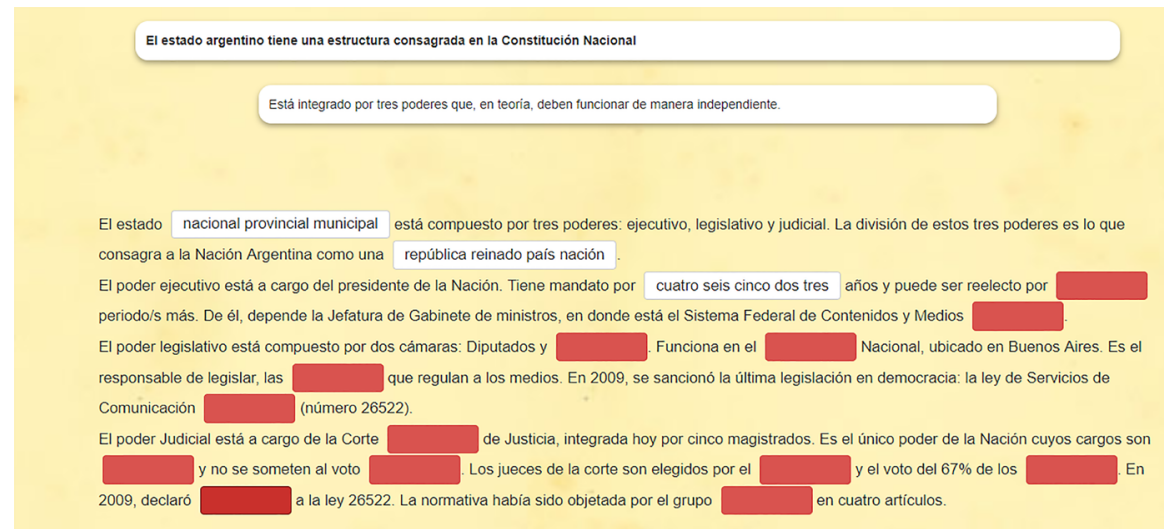

Figura 11. Recorridos del análisis del discurso, con actividades interactivas Fuente: Assinnato y Coscarelli (2018) 


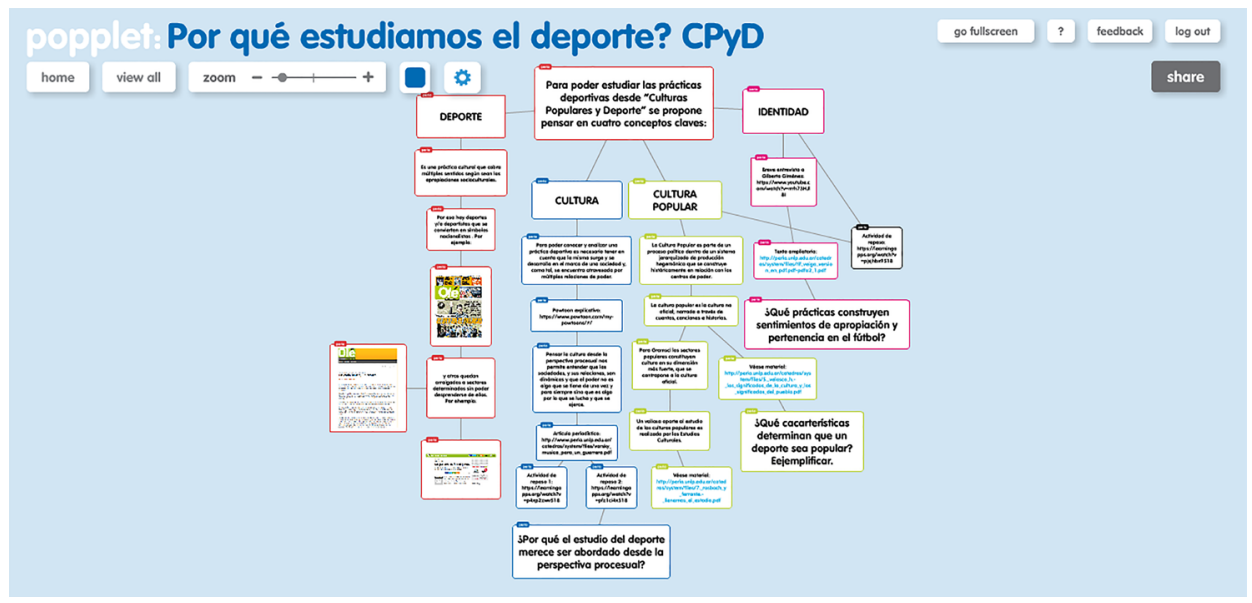

Figura 12. ¿Por qué estudiamos el deporte?, realizado por Cátedra de Cultura Popular y Deporte (FPyCS-UNLP). También ofrece pautas de análisis, lecturas de discursos y actividades

Fuente: Assinnato y Coscarelli (2018).

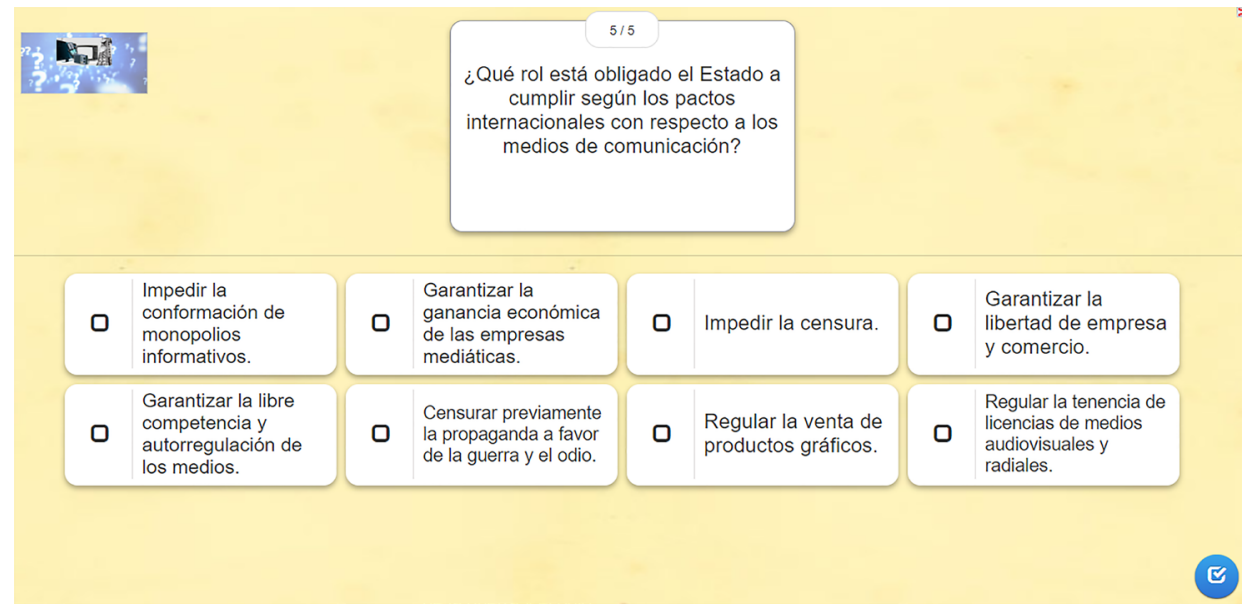

Figura 13. Material interactivo realizado por Cátedra Taller de Análisis de la Información (FPyCS-UNLP)

Fuente: Assinnato y Coscarelli (2018) 
En cuanto al segundo curso, se ponderó la participación en las clases presenciales y actividades en línea, que incluían la sistematización de las diversas herramientas conceptuales trabajadas y experiencias prácticas con asistentes y programas. A modo de recapitulación, los cursantes realizaron una propuesta educativa cuya fundamentación recuperó aspectos teóricos compartidos, en la cual, además, desarrollaron materiales digitales con herramientas como Popplet, Powtoon, LearningApps, Trainning Lyrics, Padlet, Emaze, Genially, Quizcreator, entre otras. Se destaca que, en la mayoría de los casos, se generaron proyectos situados con el fin de desarrollarse próximamente en sus espacios de desempeño. En los siguientes links, se incluyen algunas producciones realizadas por los participantes:

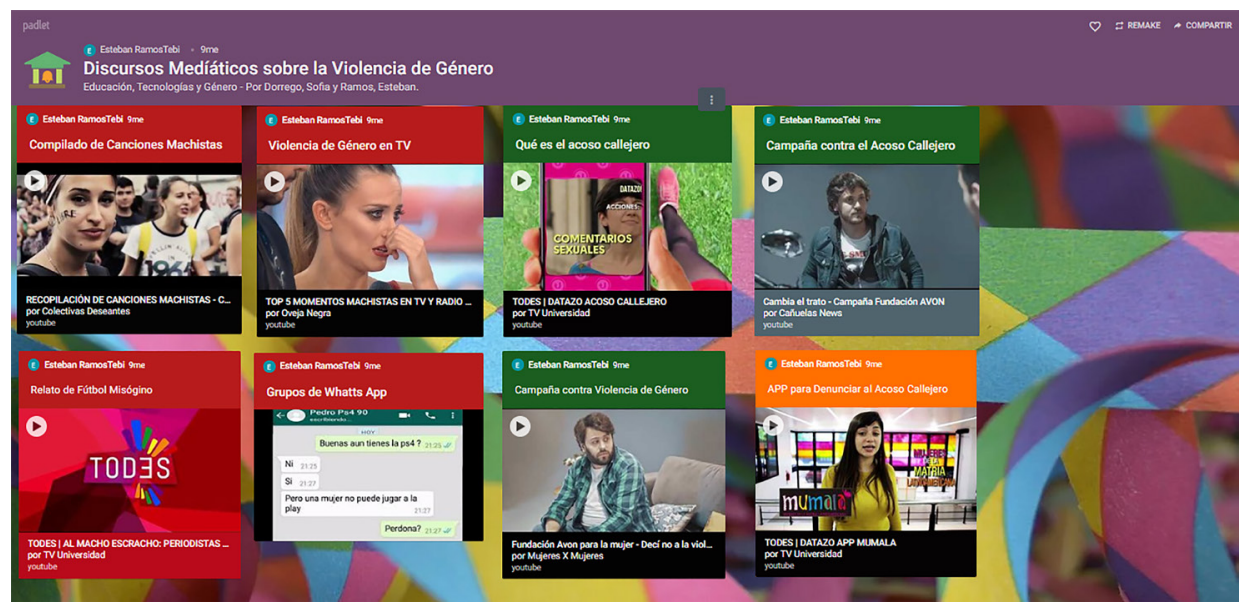

Figura 14. Proyecto Violencia de Género en Curso de Ingreso (FPyCS-UNLP). Mural realizado en Paddlet sobre discursos mediáticos

Fuente: Assinnato y Coscarelli (2018)

Juego de preguntas sobre

Violencia de Género en Curso de

Ingreso - FPyCS - UNLP
Comenzar cuestionario

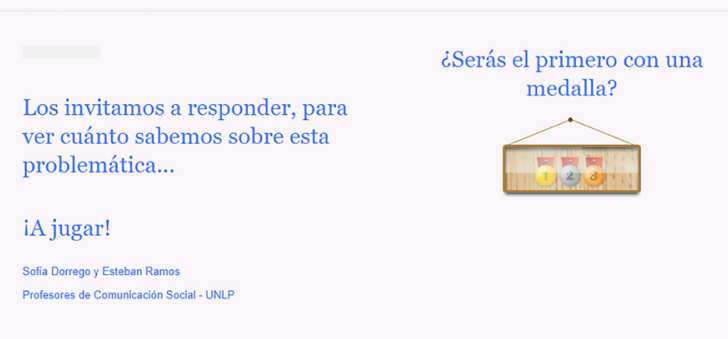

Figura 15. Juego realizado en Quiz Creator sobre violencia de género Fuente: Assinnato y Coscarelli (2018) 


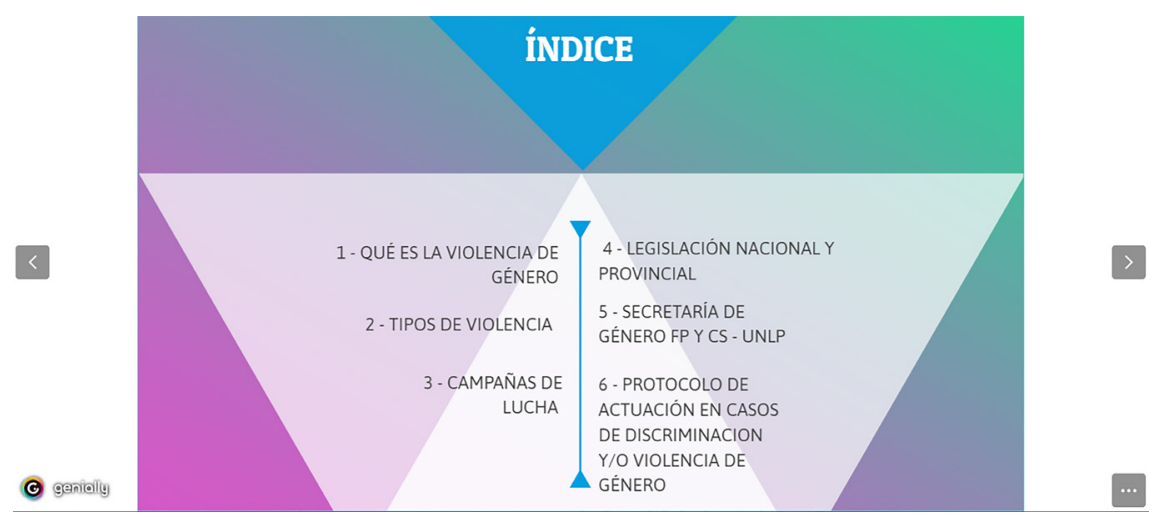

Figura 16. Presentación interactiva realizada para Curso de Ingreso (FPyCS-UNLP) Fuente: Assinnato y Coscarelli (2018)

Por último, se relevó información de las encuestas iniciales de los cursos a distancia del 2017 y el 2018, respondidas por 20 inscritos en el primer caso y 42 en el segundo. Asimismo, se observaron respuestas de cuestionarios implementados al final de cada curso. Estos eran anónimos y voluntarios, y fueron enviados por 12 participantes en el curso a distancia del 2018 y por 6 personas en el curso semipresencial del mismo año.

Sobre las respuestas de quienes participaron de estas capacitaciones se destaca lo siguiente:

En la encuesta inicial que fue administrada a veinte cursantes de "Más allá del aula: nuevas estrategias de acompañamiento al alumno", en el año 2017, se comprobó que en sus respectivas cátedras el $82 \%$ utiliza redes sociales (Facebook) y correo electrónico, y solo una cátedra usa blog, por lo que sus expectativas vinculadas con la posibilidad de incorporar otras herramientas mediadas por las nuevas tecnologías son altas. En relación con los alumnos, especialmente con los ingresantes a primer año, los integrantes de este curso de actualización a distancia esperan indagar sobre diferentes estrategias de acompañamiento, en relación con los procesos de aprendizaje que recorre cada estudiante y destacan la disposición a aprender y equivocarse, volver a aprender continuamente y la permeabilidad de los jóvenes para utilizar herramientas mediadas por TIC. Tanto adscriptos como docentes desean familiarizarse con la plataforma Moodle - utilizada en esta aula web y otras de nuestra facultad- y aplicaciones que permitan prácticas y evaluación alternativas, complementarias de las presenciales. En palabras de los mismos cursantes, en una encuesta suministrada a inicios del curso, se trata de brindar a los estudiantes diferentes formas de acreditar sus cursos cuando no han podido asistir a clase o cuando se ha agotado la cursada y sea necesaria la realización de una evaluación, o cuando resulte ineludible la exigencia de recuperación de contenidos y no sea posible su realización en clase. 
Respecto de la misma encuesta aplicada a cuarenta y dos cursantes durante la réplica en el 2018, casi todas las cátedras refieren usar Facebook, blogs, correo electrónico e internet. Algunas, Google Drive y Dropbox; muy pocas, Twitter y WhatsApp; una, Fanpage; otra, aulas web; y otra, Padlet; solo tres no usan ninguno de estos recursos. En relación con la formación profesional, sus expectativas son profundizar conocimientos en cuanto a herramientas y actividades en entornos virtuales a fin de potenciar el uso de las TIC e incorporar propuestas didácticas complementarias más dinámicas.

En lo que respecta a los cuestionarios realizados al finalizar las capacitaciones, en el caso del curso a distancia, consideran que la experiencia resultó atractiva y facilitó a los docentes capacitarse sin tener que asistir a clase, lo que suele ser generalmente una dificultad. Consideran que la dinámica fue acertada en cuanto disposición de los tiempos, organización, explicación de las consignas y relación entre teoría y práctica. Valoran la apropiación de nuevas aplicaciones y herramientas para el diseño de ejercicios autoinstruccionales y autoevaluativos, como así también para el diseño de material didáctico más lúdico, dinámico y creativo.

En el segundo curso, los asistentes valoraron en particular la problematización de las TIC y el concepto de educación mediática, las propuestas concretas en cuanto al uso posible de las aplicaciones y herramientas y su aplicabilidad en todos los niveles educativos, como así también la sencillez con que fueron abordadas.

En cuanto al desempeño docente, los participantes destacaron la claridad conceptual y la diversidad de enfoques, valoraron el enriquecimiento derivado del aporte de los invitados especiales en cada clase y la posibilidad de realizar prácticas concretas con TIC. Sugieren que se repitan o implementen cursos similares en otros contextos escolares, pero que se incremente el reconocimiento en sus ámbitos laborales (por ejemplo, en el sistema de puntaje asignado a maestros y profesores de educación pública), teniendo en cuenta la carga horaria y las prácticas realizadas.

\section{CONCLUSIONES}

Respecto de la primera unidad de análisis, los usos, las prácticas y las posiciones de los docentes en materia de integración de TIC en la enseñanza, se halló que los profesores utilizan TIC asiduamente para mantener el contacto con el alumnado y guiarlo en la resolución de actividades didácticas. También, para mediar los contenidos a partir de múltiples formatos digitales (especialmente videos) y complementar y preparar las clases presenciales. Correo electrónico, espacios virtuales de almacenamiento compartido y redes sociales son las herramientas mencionadas como las de mayor frecuencia de uso en estos escenarios de formación. 
A partir de tales datos, se puede inferir que los actores consultados han superado un acercamiento inicial a las tecnologías digitales, para escalar a niveles de adaptación de ellas, en tanto adquieren estos usos un rol permanente en los procesos de formación. No obstante, los datos aquí expuestos no permiten vislumbrar que estas experiencias den cuenta de procesos de apropiación e innovación educativa, ya que las posibilidades de creación y construcción colectiva del conocimiento relevadas registran frecuencias menos asiduas (Assinnato, 2018).

De la misma manera, no podrían concebirse como "tradicionales" los modos en que los educadores llevan adelante estrategias didácticas que integren TIC, sino que, de alguna manera, están mediando o negociando sus desempeños, aunque todavía encuentran dificultades para consolidar estas dinámicas.

En cuanto a las opiniones registradas, se vislumbra un amplio nivel de aceptación y confianza en los beneficios que las TIC podrían conllevar en los procesos educativos del nivel superior, así como también muestran una amplia predisposición a sumarse a iniciativas para profesionalizar, articular y extender experiencias aisladas de integración de TIC.

Estas percepciones favorables no son condicionadas por los extendidos juicios reprobatorios sobre las condiciones institucionales que, de acuerdo con las valoraciones docentes, serían los mayores obstaculizadores de la integración de tecnología digital. También, se puede deducir que la consolidación de estas innovaciones se representa como una demanda institucional y no solo como parte de las tareas de las cátedras o educadores. Se evidencia una tensión en lo que se pide a la institución, por lo que cada docente busca abrir sus respectivos lugares y formas de trabajo. Cabe marcar, en esta línea, que las propuestas de capacitación institucional de índole voluntaria no cuentan con una adscripción masiva por parte del profesorado de la unidad académica.

Sobre los resultados de la sistematización de las experiencias en capacitación llevadas a cabo entre el 2017 y el 2018, se desprenden datos que podrían articularse con lo desarrollado anteriormente. Pues, de acuerdo con los diagnósticos realizados por las profesoras responsables de los cursos, si bien algunas cátedras o docentes utilizan Facebook, Twitter, WhatsApp, blogs, correo electrónico e internet, o comparten documentos mediante Google Drive y Dropbox, muy pocos diseñan material didáctico y ejercicios mediante aplicaciones similares a las propuestas en ambos cursos. Tampoco usan plataformas educativas.

De allí que los resultados obtenidos logren el impacto esperado en las pequeñas cohortes conformadas, pues al finalizar ambos cursos se observa una interesante integración, diversidad y creatividad en las producciones individuales y grupales de los asistentes. Asimismo, se nota un aprovechamiento de las nuevas herramientas, en tanto 
y en cuanto surgen de contenidos y demandas reales de cada cátedra o materia en los diversos niveles (primario, secundario y universitario), y presentan un amplio margen de aplicabilidad en el futuro.

Consideramos que las capacitaciones han cumplido sus objetivos principales relacionados con la reflexión docente acerca de la incidencia de los nuevos modos de enseñar y aprender, debido a que esto resulta posible toda vez que nos colocamos en nuestro doble rol de docentes y alumnos, tomando conciencia de nuestra condición de prosumidores, en tanto consumidores y productores de materiales multimediales e hipertextuales, como protagonistas activos en el contexto de la cultura digital. También creemos que el tránsito de la teoría a la práctica es posible de modo simple, si se enfatiza en la optimización de tiempos y el aporte de los diversos actores educativos (alumnos, docentes, coordinadores y colaboradores o especialistas).

Recuperando los aportes del marco conceptual, entendemos que la mayoría de las prácticas de la formación permitieron atravesar una experiencia situada, en la cual se ubican las tecnologías como instrumentos mediadores de las relaciones entre los alumnos y los contenidos de aprendizaje, como instrumentos mediadores de las relaciones entre los profesores y los alumnos, o entre los alumnos, y, además, como instrumentos mediadores - cuando menos, incipientes- de los modos de construcción de conocimiento, con un rol activo por parte de los estudiantes.

Se trata de situaciones de enseñanza y aprendizaje que tensan lo nuevo y lo viejo y podrían delimitar una línea de cambios valiosos y complejos a la vez que reconfigurar las tradicionales prácticas educativas por otras más innovadoras, sin perder el sentido crítico y transformador del nivel universitario en cuestión.

Así, vemos una línea de trabajo en materia de capacitación y formación profesional que podría hacer aportes valiosos al esfuerzo docente por incorporar los recursos digitales como parte de los métodos de enseñanza y aprendizaje.

Queda pendiente, no obstante, un trabajo a largo plazo y sostenido acerca de la alfabetización académica mediada por tecnologías digitales que facilite y fortalezca la producción de hipertextos multimediales, el trabajo colaborativo y la gestión pedagógica de actividades presenciales y virtuales con TIC, demanda que se vislumbra en algunas de las encuestas a quienes participaron de ambas propuestas como docentes de los niveles superiores.

Se trata de un trabajo a largo plazo que debería indagar, además, cuáles son los motivos por los que una buena parte del profesorado no participa de tales escenarios de formación, lo que llevaría a repensar otras formas de convocatoria docente, estrategias y metodologías de acompañamiento docente diversas, entre otras, con el fin de traccionar y consolidar cambios e innovaciones educativas más estables, genuinas y sostenidas en la institución. 


\section{REFERENCIAS}

Assinnato, G. (2018). Estrategias de integración de tecnologías de información y comunicación en procesos de enseñanza y aprendizaje de nivel universitario [Tesis de Maestría]. Argentina: Facultad de Informática, Universidad Nacional de La Plata. Recuperado de shorturl.at/jxS06

Assinnato, G. y Coscarelli, A. (2018). Informe final de experiencias mediadas por TIC. Documento interno de la Secretaría Académica de la Facultad de Periodismo y Comunicación Social, Universidad Nacional de La Plata (FPyCS UNLP). Recuperado de https://bit.ly/2GkPAaf

Assinnato, G., Mateus, J. C. y Novomisky, S. (2018). Las TIC en la enseñanza universitaria de la comunicación: usos, sentidos y representaciones en dos universidades de Argentina y del Perú. Communication Papers, 14. Recuperado dehttps://bit. ly/20CqNnf

Barberá Gregori, E. y Badia, A. (2005). El uso educativo de las aulas virtuales emergentes en la educación superior. Revista de Universidad y Sociedad del Conocimiento (RUSC) 2(2). Recuperado de http://goo.gl/s8KPXW UOC

Bilinkis, S. (2014). Pasaje al futuro. Buenos Aires: Sudamericana.

Cabello, R. (2006). Yo con la computadora no tengo nada que ver. Un estudio de las relaciones entre los maestros y las tecnologías informáticas en la enseñanza. Buenos Aires: Prometeo y Universidad Nacional General Sarmiento.

Cabero-Almenara, J. (2014). Formación del profesorado universitario en TIC. Aplicación del método Delphi para la selección de los contenidos formativos. Educación XXI, 17(1), 111-131.

Coll, C. (2009). Aprender y enseñar con las TIC: expectativas, realidad y potencialidades. En Carneiro, R., Toscano J. C. y T. Díaz (coords.), Los desafíos de las TIC para el cambio educativo, pp. 111-126. España, OEl- Fundación Santillana.

García Valcárcel A. y González Rodero, L. (2006). Uso pedagógico de materiales y recursos educativos de las TIC: sus ventajas en el aula. España: Universidad de Salamanca, Colección Educ.ar. Recuperado de http://goo.gl/wd1Lzn.

Guiller, C. M. y Arce, D. M. (2013). Gestión de experiencias educativas universitarias mediadas por TIC en la Facultad de Periodismo y Comunicación Social (UNLP): aula extendida y educación a distancia. Revista Question, Vol. 1 (39). Recuperado de https://goo.gl/UbnFCr

Guiller, C. M. y Arce, D. M. (2015). Los entornos virtuales: nuevos escenarios de enseñanza y aprendizaje en la universidad. Recuperado de http://hdl.handle. net/10915/52290 
Guiller, C. M. y Arce, D. M. (2017). ¿Cómo se da el pasaje de docente presencial a virtual? Notas y posicionamientos en torno a una experiencia de reconfiguración del rol en el ámbito universitario. Recuperado de http://hdl.handle.net/10915/66338

Kuklinski, H. P. y Balestrini, M. (2010). Prototipos de Mobile Open Education: una breve selección de casos. IEEE-RITA, 5(4), 125-131.

Litwin, E. (Comp.). (2005). La tecnología educativa en el debate didáctico. En Tecnologías educativas en tiempos de internet. Buenos Aires: Amorrortu.

Nóbile, C. y Sanz, C. (2014) Procesos de integración de tecnologías de la información y la comunicación en instituciones de educación superior. El caso de la Facultad de Ciencias Económicas de la Universidad Nacional de La Plata. Tesis de Maestría en Tecnología Informática Aplicada en Educación. Facultad de Informática, Universidad Nacional de La Plata.

Noguera, H. R. y Vásquez Melo, L. (2012). Formación del docente universitario en el uso de TIC. Caso universidades públicas y privadas. (U. de Carabobo y U. Metropolitana). Revista de Medios y Educación, (41), 163-171.

Ozdamli, F. y Cavus, N. (2011). "Basic elements and characteristics of mobile learning", Procedia-Social and Behavioral Sciences, 28(1), 937-942.

Ros, C. (Coord.) (2014). Inclusión digital y prácticas de enseñanza en el marco del Programa Conectar Igualdad para la formación docente. Buenos Aires: Ministerio de Educación de la Nación.

TV Universidad Nacional de La Plata [TV universidad]. (2018, octubre 24). Proyecto NEXOS - UNLP. Cap.4: Las TIC [Archivo de video]. Recuperado de: https://bit.ly/2rBdhTX

Valencia, A., González, G. y Castañeda, M. (2016). Structural equation model for studying the mobile-learning acceptance. IEEE Latin America Transactions, 14(4), 1988-1992.

Valencia-Arias, A., Benjumea Arias, M. L., Morales Zapata, D., Silva Cortés, A. y Betancur Zuluaga, P. (2018). Actitudes de docentes universitarios frente al uso de dispositivos móviles con fines académicos. Revista mexicana de investigación educativa, 23(78), 761-790.

Valverde Berrocoso, J., Garrido Arroyo, M. C. y Fernández Sánchez, R. (2010). Enseñar y aprender con tecnologías: un modelo teórico para las buenas prácticas con TIC. En Teoría de la Educación. Educación y Cultura en la Sociedad de la Información, pp. 203-229. Salamanca: Universidad de Salamanca. 